\title{
Effects of Microvascular Decompression Plus Longitudinal Nerve Sectioning on Recurrent Trigeminal Neuralgia and Investigations of Postoperative Recurrence Causes
}

\author{
Luo CONG, Cheng ZHIHUA, Guo ZHILIN, Ou Yang HUONIU \\ Shanghai Jiao Tong University, School of Medicine, Shanghai Ninth People's Hospital, Department of Neurosurgery, Shanghai, China
}

Corresponding author: Zhilin GUO 13262626183@163.com

\section{ABSTRACT}

AIM: To investigate the causes of recurrent trigeminal neuralgia (RTN) and to evaluate the efficacy of microvascular decompression (MVD) plus longitudinal nerve sectioning (LNS) or LNS only for RTN patients who have undergone multiple procedures.

MATERIAL and METHODS: Twenty one patients underwent MVD plus LNS or LNS only at our institute from June 2008 to December 2014. The patients were retrospectively reviewed and analyzed. The following data were collected: age, sex, treatment before surgery, pain severity and distribution, findings during surgery, immediate postoperative BNI (Barrow Neurological Institute score system), final follow-up BNI, complications and associated comorbidities.

RESULTS: Vascular compression, arachnoid adhesion and Teflon granulomas were the primary causes of RTN. After MVD plus LNS or LNS only treatments, almost all patients (19/21, 90.5\%) reported pain relief after 36.1 months. Of these patients, 15 patients (71.4\%) reported being pain-free (BNI score I) and 4 patients (19.1\%) reported pain relief (BNI II-III). Two patients reported a pain level of BNI IV. However, almost all patients were left with some degree of numbness.

CONCLUSION: This study certified that vascular compression, arachnoid adhesion and Teflon granulomas were the reasons for RTN. MVD plus LNS or LNS only were both feasible therapeutic options, with good probabilities of success, especially after multiple neurodestructive procedures.

KEYWORDS: Microvascular decompression, Longitudinal nerve sectioning, Recurrent trigeminal neuralgia, Vascular compression, Arachnoid adhesion, Teflon granuloma

\section{INTRODUCTION}

I diopathic trigeminal neuralgia $(\mathrm{TN})$ is a facial pain syndrome. The incidence of idiopathic TN is reported as 1 to 2/10000 (21). It is usually qualified by sharp, paroxysmal, unilateral and electric shock-like pain in branches of the trigeminal nerve, accompanied with innocuous triggers (25). However, the exact pathophysiology of TN is not well studied yet. As reported, the leading etiology hypothesis focuses on vascular compression at the root entry zone (REZ) of the trigeminal nerve $(17,23,28)$. The effectiveness of microvascular decompression (MVD) for idiopathic TN supports this argument $(3,24,35)$.
Studies have shown that the success rate of MVD tends to reduce over time. Approximately $22-42 \%$ of patients suffer from recurrent TN 5 years after MVD treatment, and careful decisions with respect to additional treatment must be made $(5,24)$. Whether to use surgical or non-surgical methods to treat patients with recurrent TN has long been a controversial issue, and potential treatments include MVD, percutaneous glycerol rhizotomy, percutaneous radiofrequency rhizotomy, stereotactic radiosurgery, and percutaneous balloon compression. The purpose of this study was to discuss the outcomes of MVD plus LNS or LNS only for patients with recurrent TN.

Luo CONG (1) : 0000-0001-5822-446X

Ou Yang HUONIU (D) : 0000-0003-1302-8902 
Cong L. et al: Recurrent Trigeminal Neuralgia

We also explored the possible causes of the disorder based on the observations during surgery.

\section{- MATERIAL and METHODS}

This study was approved by the institutional review board of Shanghai Ninth People's Hospital.

\section{Inclusion and Exclusion Criteria}

A total of 376 patients with idiopathic TN accepted to undergo surgery at the department of Neurosurgery of our hospital from June 2008 to December 2014. Among them, 21 patients suffered from recurrent TN, even after several destructive surgical treatments, and ultimately accepted a treatment protocol of MVD plus LNS or LNS alone. The primary indications were typical, drug-resistant TN (the International Headache Society criteria), or drug-responsive TN but with severe drugrelated adverse effects, without absolute contraindications to general anesthesia (12). The exclusion criteria were as follows: 1) patients who had failed initial surgeries; 2) patients who had a pain-free period after the initial surgical treatment; 3) patients with absolute contraindications to general anesthesia; 4) patients who did not choose MVD plus LNS treatment for recurrent $\mathrm{TN}$; 5) patients whose data were not complete; and 6) patients who had any other surgery in the posterior fossa, such as tumor removal, vascular malformations and congenital malformations.

\section{Data Collection}

The medical records of all patients were reviewed. The data collected, included age, sex, treatment before surgery, pain severity and distribution, findings during surgery, immediate postoperative $\mathrm{BNI}$, final follow-up BNI, associated comorbidities (e.g., cardiovascular diseases, arterial hypertension, and diabetes), and complications. The severity of pre- and postoperative pain was scored using the Barrow Neurological institute (BNI) Pain Intensity Scale Score. Statistics were analyzed with the mean, minimum and maximum range for continuous data. The enumeration data were expressed as percentages.

\section{Surgical Procedures}

MVD plus LNS was performed through a suboccipital restrosigmoid approach. Briefly, the patients were placed in the supine position, with the affected side up, the ear parallel to the floor, and the chin flexed (22). A standard $5 \mathrm{~cm}$ to 7 $\mathrm{cm}$ linear retroauricular incision was made. Then, if necessary, the existing cranioplasty material was completely removed. We removed the additional bone to visualize the edges of the sigmoid sinus and the transverse sinus. The craniotomy required was less than $3 \times 2 \mathrm{~cm}$. The dura was incised to form a flap, and the upper external posterior cranial fossa was fully exposed until the trigeminal nerve roots were clearly observed. The arachnoid membrane surrounding the trigeminal nerves was opened to expose REZ.

During the surgery, new Teflon felt pieces were used to separate the third nerve from the offending vessels. Then, the nerve fibers were divided longitudinally into several respective bundles, from the REZ to the petrous bone, by using a straight blunt-tip bayonet probe. If necessary, the fibers were combed without evidence of compression. After surgery, the surgical incision was closed very carefully. During the surgery, the medical microscope video recorder system was used to record the intracranial details. All patients included in this study were operated on by one neurosurgeon, Zhi-Lin Guo.

\section{Follow-up and the Post-Operative Outcome Assessments}

All patients were telephoned and outpatient follow-ups were performed. The follow-up period ended on October 30, 2016. The Barrow Neurological Institute (BNI) scoring system was used to evaluate the degree of pain relief. According to Figure 4 , the TN was divided into five grades, depending on the severity of pain and the response to medicine (27). Independent observers, who were not involved in patient management or surgeries, managed follow-ups through outpatient services or telephone and also recorded complications and recurrences. General inquiry, facial nerve tests and hearing tests were performed during the follow-ups.

\section{RESULTS}

A total of 376 patients were analyzed in this study, of whom 150 were men and 226 were women. The mean age at MVD was $58.2 \pm 10.3$ years old (range: $26.4-78.7$ years). The length of follow-up was from 21 to 98 months (mean: $59.2 \pm 26.3$ months). There were 18 patients with diabetes mellitus, 27 with cardiovascular disease and 96 with arterial hypertension. The demographic characteristics of the patients in our study are shown in Table I. Among them, 21 patients suffered from recurrent TN after multiple destructive surgical treatments, performed at other medical institutions, including microvascular decompression (MVD), percutaneous glycerol rhizotomy (PGR), stereotactic radiosurgery (SRS), botulinum neurotoxin (BoNT) and percutaneous balloon compression (PBC) (Table II). Ultimately 12 patients accepted MVD plus

Table I: Demographics and Characteristics of Patients

\begin{tabular}{lc}
\hline Characteristics & Value \\
\hline Number of patients who underwent MVD & 376 \\
\hline Male/female ratio & $150 / 226$ \\
\hline Male sex, n (\%) & $150(39.9)$ \\
\hline Age at surgery, years & $58.2 \pm 10.3$ \\
\hline Median & $26.4-78.7$ \\
\hline Range & $21-98$ \\
\hline Follow-up range (months) & $59.2 \pm 26.3$ \\
\hline Mean follow-up & 18 \\
\hline Comorbidities & 27 \\
\hline Diabetes mellitus & 96 \\
\hline Cardiovascular disease & \\
\hline Arterial hypertension & \\
\hline
\end{tabular}


LNS, and 9 patients accepted LNS alone, at the Department of Neurosurgery of Shanghai Ninth People's Hospital. Of these, 6 patients experienced facial numbness prior to the procedure.

All 21 patients experienced unilateral and electric shocklike pain, 8 on the left side and 13 on the other side. They had experienced recurrent pain for 3-18 months (mean $8 \pm$ 4.3 months) and depended on drugs for pain relief to varying degrees (Table II). The mean age of the patients at the time of surgery was $59.6 \pm 11.0$ years old (range 39-78 years old). The follow-up period after the latest surgery ranged from 22 to 68 months (mean $38.3 \pm 15.2$ months). During the followup period, relief from symptoms was observed in all cases. The demographic characteristics of the patients are shown in Table II.

\section{Preoperative Imaging and Operative Findings}

The pre-operative MRTA of 18 patients (18/21, 85.7\%) showed positive results, consistent with the observations during operations. During the surgery the following were discovered: arterial compression in 7 patients (33.3\%); venous compression in 2 patients (4.8\%); arterial combined with venous compression in 2 patients (9.5\%); Teflon granulomas in 1 patient $(4.8 \%)$; and nothing except arachnoid adhesion in 9 cases $(42.9 \%)$ (Table III). Arachnoid adhesion was found in 20 out of the 21 patients $(95.2 \%)$ and was dissected during surgery.

Teflon granulomas have been considered to be responsible for recurrent TN. During the operations, a Teflon granuloma was found in the cerebellopontine angle and was in touch with the trigeminal nerve in 1 of the 21 patients. As shown in Figure 1, the mass was a low-intensity signal in the T2-weighted MRI

Table II: Demographics and Characteristics of Patients Undergoing MVD Plus LNS or LNS Only

\begin{tabular}{|c|c|c|c|c|c|c|}
\hline $\begin{array}{l}\text { Patient } \\
\text { No. }\end{array}$ & Sex & Age & $\begin{array}{l}\text { Duration of } \\
\text { symptoms before } \\
\text { the procedure }\end{array}$ & $\begin{array}{c}\text { Pain distribution } \\
\text { before the procedure }\end{array}$ & $\begin{array}{c}\text { Follow-up duration } \\
\text { after the procedure, } \\
\text { months }\end{array}$ & $\begin{array}{l}\text { Other treatments } \\
\text { before the procedure }\end{array}$ \\
\hline 1 & $\mathrm{~F}$ & 49 & 18 & R V2 & 32 & MVD, BoNT \\
\hline 2 & $\mathrm{~F}$ & 66 & 5 & R V3 & 23 & MVD, SRS \\
\hline 3 & $\mathrm{~F}$ & 62 & 7 & R V2 & 68 & MVD, PBC \\
\hline 4 & $\mathrm{~F}$ & 39 & 6 & L V2 & 60 & MVD, PGR \\
\hline 5 & $\mathrm{~F}$ & 63 & 4 & L V2V3 & 26 & MVD, PBC \\
\hline 6 & M & 50 & 17 & R V1 & 48 & MVD, SRS \\
\hline 7 & $\mathrm{~F}$ & 64 & 3 & R V2 & 24 & MVD, SRS, PBC, BoNT \\
\hline 8 & $\mathrm{~F}$ & 69 & 7 & L V2 & 37 & MVD, BoNT \\
\hline 9 & M & 63 & 12 & R V2 & 33 & MVD, PBC \\
\hline 10 & $\mathrm{~F}$ & 41 & 3 & L V2 & 25 & MVD, SRS \\
\hline 11 & M & 55 & 7 & R V2 & 28 & MVD, SRS \\
\hline 12 & $\mathrm{~F}$ & 70 & 5 & RV3 & 27 & MVD, SRS \\
\hline 13 & $\mathrm{M}$ & 60 & 7 & $\mathrm{RV} 2$ & 28 & MVD, BoNT \\
\hline 14 & M & 69 & 6 & $\mathrm{RV} 2$ & 27 & MVD, SRS, BoNT \\
\hline 15 & $\mathrm{~F}$ & 41 & 11 & LV1 & 35 & MVD, BoNT, SRS \\
\hline 16 & M & 78 & 14 & RV3 & 58 & MVD, PBC \\
\hline 17 & $\mathrm{~F}$ & 70 & 10 & LV2 & 57 & MVD, SRS \\
\hline 18 & $\mathrm{~F}$ & 49 & 4 & LV2 & 66 & MVD, SRS \\
\hline 19 & M & 59 & 6 & RV3 & 22 & MVD, SRS \\
\hline 20 & $\mathrm{~F}$ & 69 & 7 & $\mathrm{RV} 2$ & 33 & MVD, PGR \\
\hline 21 & $\mathrm{M}$ & 66 & 9 & LV2 & 47 & MVD, PBC \\
\hline
\end{tabular}

F: Female, M: Male, R: Right, L: Left, V1: The first branch of trigeminal nerve, V2: The second branch of the trigeminal nerve, V3: The third branch of the trigeminal nerve, MVD plus LNS: Microvascular decompression in combination with longitudinal nerve sectioning, MVD: Microvascular decompression, PGR: Percutaneous glycerol rhizotomy, PBC: Percutaneous balloon compression, SRS: Stereotactic radiosurgery, BoNT: Botulinum neurotoxin. 
Cong L. et al: Recurrent Trigeminal Neuralgia

Table III: Magnetic Resonance Tomographic Angiography and Operative Findings in 21 Patients

\begin{tabular}{|c|c|c|c|c|c|c|c|}
\hline \multirow{2}{*}{$\begin{array}{c}\text { Patients } \\
\text { No. }\end{array}$} & \multirow{2}{*}{$\begin{array}{c}\text { MRTA } \\
\text { before the } \\
\text { procedure }\end{array}$} & \multirow[b]{2}{*}{ the procedure } & \multirow{2}{*}{$\begin{array}{l}\text { Findings during the } \\
\text { surgery }\end{array}$} & \multicolumn{3}{|c|}{ the procedure } & \multirow[b]{2}{*}{ Comorbidities } \\
\hline & & & & Pre-op BNI & $\begin{array}{l}\text { Immediate } \\
\text { post-op BNI }\end{array}$ & $\begin{array}{l}\text { Final follow- } \\
\text { up BNI }\end{array}$ & \\
\hline 1 & $\mathrm{P}$ & LNS & AA only & IV & 1 & II & $\mathrm{AH}$ \\
\hline 2 & $\mathrm{P}$ & LNS & AA only & IV & 1 & I & NO \\
\hline 3 & $\mathrm{P}$ & MVD+LNS & $\mathrm{AICA}+\mathrm{PV}+\mathrm{AA}$ & V & 1 & IV & $\mathrm{AH}$ \\
\hline 4 & $\mathrm{P}$ & LNS & AA only & IV & 1 & I & $\mathrm{AH}$ \\
\hline 5 & $\mathrm{P}$ & LNS & AA only & V & 1 & 1 & NO \\
\hline 6 & $\mathrm{~N}$ & MVD+LNS & $\mathrm{PV}+\mathrm{AA}$ & V & $\|$ & IV & NO \\
\hline 7 & $p$ & MVD+LNS & $\mathrm{AICA}+\mathrm{AA}$ & V & I & I & NO \\
\hline 8 & $P$ & MVD+LNS & $\mathrm{AlCA}+\mathrm{AA}$ & IV & I & I & NO \\
\hline 9 & $p$ & LNS & AA only & IV & 1 & I & NO \\
\hline 10 & $P$ & MVD+LNS & $\mathrm{AICA}+\mathrm{AA}$ & V & 1 & II & NO \\
\hline 11 & $\mathrm{P}$ & LNS & AA only & V & 1 & 1 & $\mathrm{AH}$ \\
\hline 12 & $\mathrm{P}$ & MVD+LNS & $\mathrm{SCA}+\mathrm{AA}$ & $\mathrm{V}$ & 1 & 1 & NO \\
\hline 13 & $\mathrm{~N}$ & MVD+LNS & $\mathrm{PV}+\mathrm{AA}$ & V & 1 & II & NO \\
\hline 14 & $\mathrm{P}$ & MVD+LNS & AICA & IV & 1 & 1 & $\mathrm{AH}$ \\
\hline 15 & $\mathrm{P}$ & LNS & AA only & V & 1 & 1 & $\mathrm{AH}, \mathrm{CD}$ \\
\hline 16 & $\mathrm{p}$ & MVD+LNS & $\mathrm{AlCA}+\mathrm{AA}$ & IV & 1 & 1 & NO \\
\hline 17 & $\mathrm{P}$ & MVD+LNS & $\mathrm{SCA}+\mathrm{AA}$ & IV & 1 & ॥ & $\mathrm{AH}$ \\
\hline 18 & $\mathrm{P}$ & MVD+LNS & $\mathrm{AlCA}+\mathrm{PV}+\mathrm{AA}$ & V & 1 & 1 & NO \\
\hline 19 & $\mathrm{~N}$ & LNS & AA only & IV & 1 & 1 & $\mathrm{AH}$ \\
\hline 20 & $\mathrm{P}$ & MVD+LNS & Teflon granuloma+AA & V & II & III & NO \\
\hline 21 & $\mathrm{P}$ & LNS & AA only & V & 1 & 1 & NO \\
\hline
\end{tabular}

MVD plus LNS: Microvascular decompression in combination with longitudinal nerve sectioning, MVD: Microvascular decompression, P: Positive, N: Negative, SCA, AICA, AA: Arachnoid adhesion, PV: Petrosal vein, AH: Arterial hypertension, CD: cardiovascular diseases.
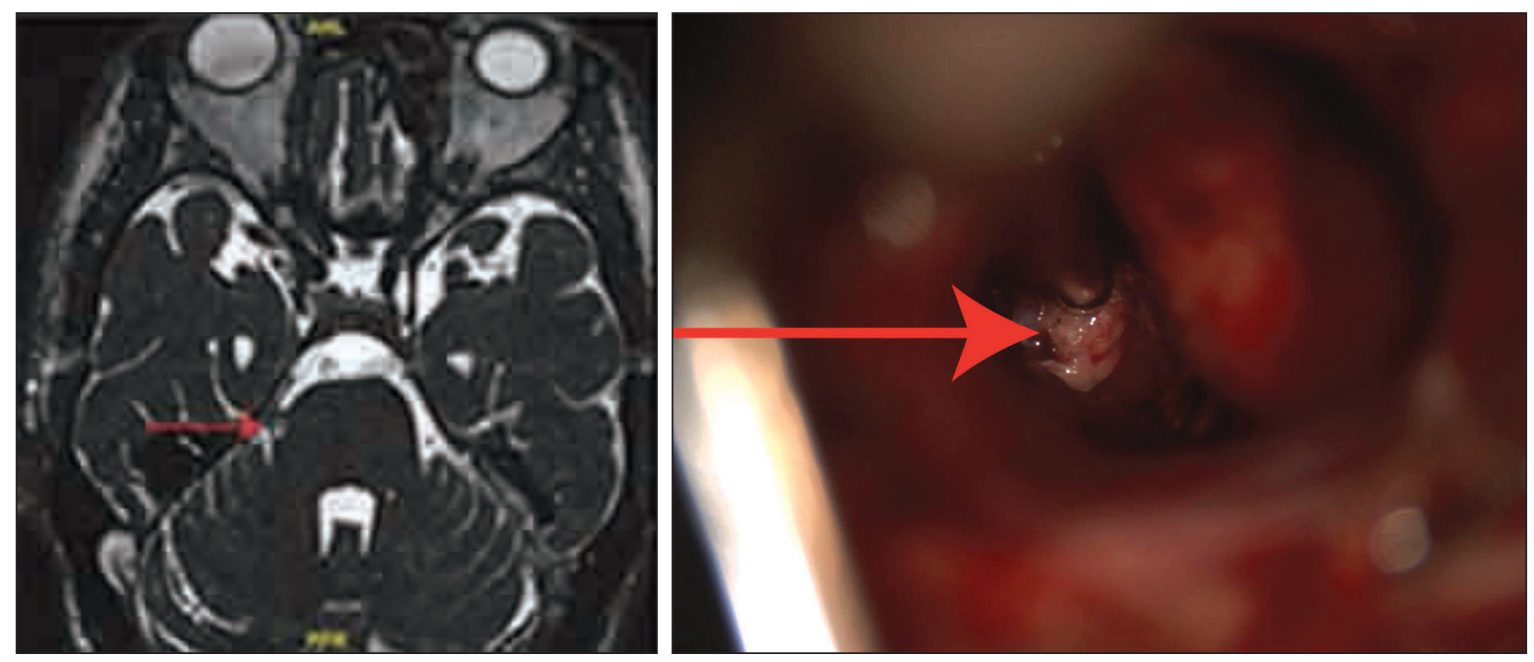

Figure 1: Brain MRI and an intraoperative photograph showing that a Teflon granuloma (arrowhead) compressed the right trigeminal nerve. 

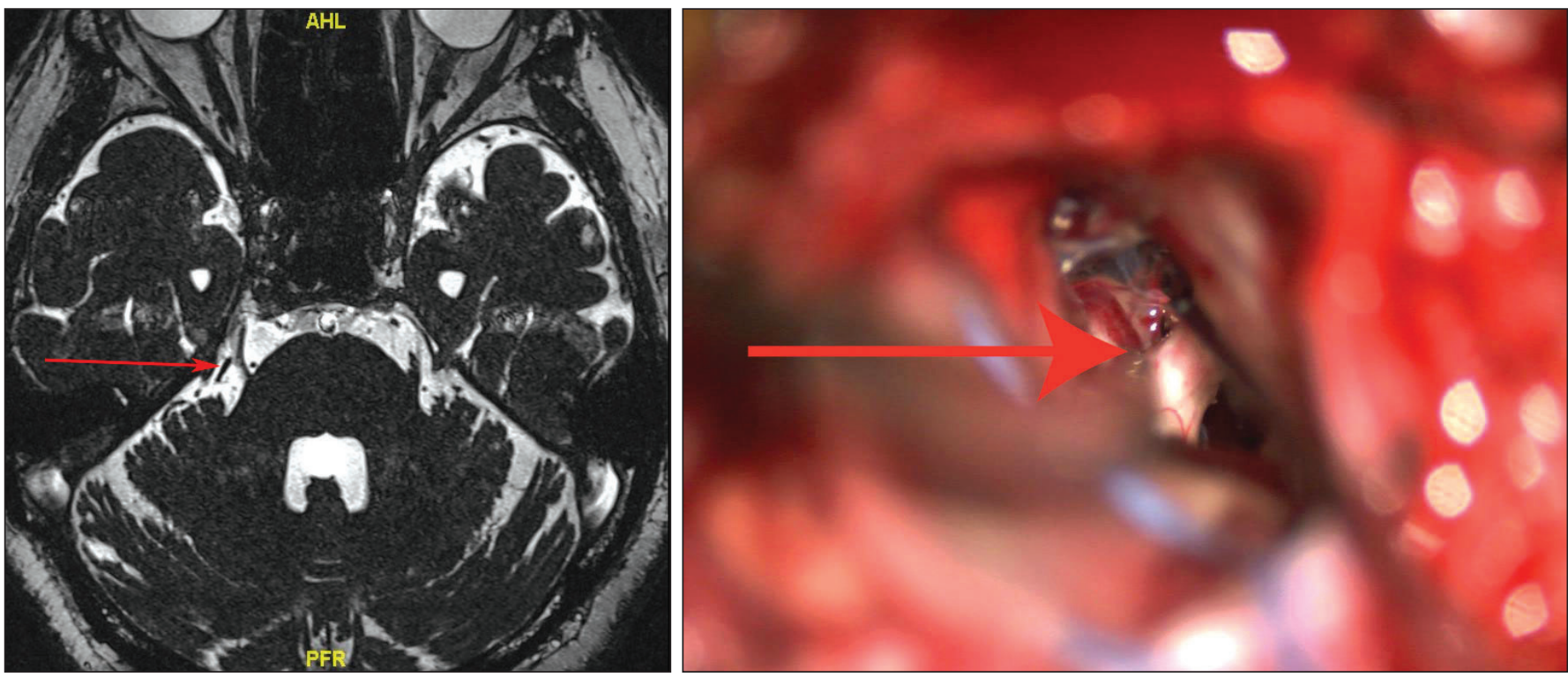

Figure 2: Brain MRI and an intraoperative photograph showing a new defending venous (arrowhead) compression on the right trigeminal nerve.

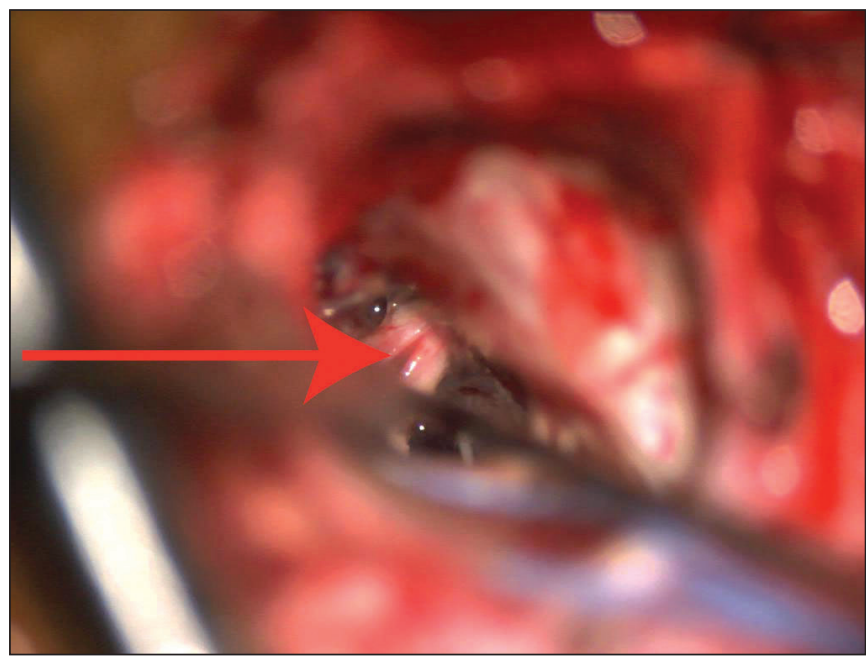

Figure 3: Brain MRI and an intraoperative photograph showing that the right trigeminal nerve fibers were gently combed.

under MRTA. During the surgical procedures, the mass was removed and the nerve fibers were combed gently, as seen in Figure 3.

\section{Follow-up and Outcome Assessments}

The MVD plus LNS or LNS only treatments offered a high degree of pain relief for patients suffering from recurrent TN pain. All 21 patients reported immediate pain relief after the surgeries. Among them, 19 cases $(90.5 \%)$ had a BNI score of I, and 2 cases $(9.5 \%)$ had a BNI score of II (Table III). At the end of the follow-up period, 15 patients $(71.4 \%)$ had BNI I, 3 cases (14.3\%) had BNI II and 1 case (4.8\%) experienced BNI III. The final 2 patients $(9.5 \%)$ had BNI scores of IV and controlled their pain with medication.

\section{Complications of MVD plus LNS or LNS Only Operations}

Complications of the operation included cerebrospinal fluid leakage in 1 patient $(4.76 \%)$ and bacterial meningitis in 1 patient (4.76\%); however, the bacterial meningitis and cerebrospinal fluid leakage were resolved after appropriate treatment. Facial numbness occurred in 21 patients (100\%) immediately after surgery and 18 patients (85.7\%) still experienced facial numbness at the end of the follow-up period. No patients died, and no sensory deficits or other cranial nerve deficits such as hearing loss were noted (Table IV).

\section{DISCUSSION}

MVD is accepted as one of the effective treatments for idiopathic TN (10). Although the long-term pain relief rate of MVD is $71 \%-84 \%$, not all patients experience recovery after the procedure $(5,10,14,24,29,30,34)$. In fact, some patients experience recurrent TN pain at a recurrence rate of $1-5 \%$ every year $(3,4,6,32)$.

The options for the effective treatment of recurrent TN patients are controversial. Only a few studies have examined the outcome of MVD plus LNS or LNS only. Percutaneous balloon compression, gamma knife surgery, and repeated MVD have previously been reported to treat patients with recurrent TN, but the results were not very satisfactory $(2,11,16,31)$. In our study, almost all patients (19/21, 90.5\%) reported pain relief 36.1 months after the procedure, 15 patients $(71.4 \%)$ reported being pain free (BNI score I), and 4 patients (19.0\%) reported pain relief (BNI II-III).

Two possible explanations for the effectiveness of this surgical method were analyzed. One explanation is that the vascular contact was dissected at the REZ of the third cranial nerve $(28,31)$. The other explanation is that the continuity of the axon was destroyed by combing the nerve, not only resulting in a 


\begin{tabular}{|l|l|}
\hline grade I & No pain, no medication \\
\hline grade II & Occasional pain, not requiring medication \\
\hline grade III & Some pain, adequately controlled with medication \\
\hline grade IV & Some pain, not adequately controlled with medication \\
\hline grade V & Severe pain/no pain relief \\
\hline
\end{tabular}

Figure 4: Barrow Neurological Institute (BNI) pain intensity scale score.
Table IV: Complications of MVD Plus LNS or LNS Only

\begin{tabular}{ll}
\hline Complication & $\mathbf{n}(\%)$ \\
\hline Mortality & 0 \\
\hline CSF leakage & $1(4.76)$ \\
\hline Facial numbness & $18(85.7)$ \\
\hline Cranial nerve deficit & 0 \\
\hline Bacterial meningitis & $1(4.76)$ \\
\hline Sensory deficits & 0 \\
\hline
\end{tabular}

reduction of the electrical excitability that was being produced by abnormal afferent trigeminal fibers, but causing partial injury to sensory nerves $(18-20,36)$. During our procedure, we found that the operative route was full of arachnoid thickening and adhesions. The arachnoid membrane bound the trigeminal nerve and could not be released by the sharpness of separation alone; we therefore added longitudinal nerve sectioning. Pain disappeared in nine patients after treatment by LNS only, and the effect was significant. Therefore, we thought the technique of MVD plus LNS could be more effective for patients who had previously received several traumatic surgeries. However, trauma to the trigeminal root does not appear to be the mechanism for facial numbness. Facial numbness could be caused by other lesioning techniques, such as BoNT, SRS, PBC or PGR. However, the MVD plus LNS or LNS only techniques can used by any surgical center where MVD can be performed, even in remote hospitals. Above all, this procedure can be performed in patients without vascular compression.

The causes of recurrent TN were commonly considered to be vascular compression and arachnoid adhesion, followed by Teflon granulomas.

In this study vascular compression involving the following components was observed: vessel loops were observed in 11 cases $(50.0 \%)$, the superior cerebellar artery was observed in 2 cases $(9.5 \%)$, the anterior inferior cerebellar artery was observed in 5 cases $(23.8 \%)$, the petrosal vein was observed in 2 cases $(9.5 \%)$, and the anterior inferior cerebellar artery combined with the petrosal vein was observed 2 cases (9.5\%). According to the records of previous operations for multiple patients, venous compression of the third cranial nerve was located and removed, and patients reported pain relief after the operations. During the procedures in our hospital, Teflon was found between the third cranial nerve and the new venous compression of the trigeminal nerve. We hypothesize that the new compression is responsible for the return of TN. Vascular compression is mainly caused by progressive blood vessel changes, which is associated with the normal aging process, such as arteriosclerosis. Arachnoid adhesions and thickening, which decrease the cerebellopontine angle area, increase the probability of blood vessels contacting the trigeminal nerve.

A Teflon granuloma, as shown in Figure 2, was found in 1 patient $(4.8 \%)$, ventral to the trigeminal nerve. As is known, Teflon granulomas occur in 1.1-7.3\% of all MVD cases performed in accordance with Jannetta's procedure $(7,8,26)$. They cause pain in $13-50 \%$ of recurrent neuralgia patients $(1,8,9)$. The most common giant cell inflammatory responses associated with Teflon applications have been described in orthopedics, maxillofacial surgery, and otolaryngology $(13,15,33)$.

Surgery can induce arachnoid thickening or unusual adhesions, which complicates the anatomical relationship between the cranial nerve and adjacent vascular structures. In our study, arachnoid adhesion was found in almost all patients (20/21, 95.2\%). Arachnoid adhesion and thickening reduce the cerebellopontine angle area, increasing the probability of blood vessels contacting the trigeminal nerve. This could help to make a connection between the trigeminal nerve and offending vessels. The pulse through the offending vessels was transmitted to the nerve more easily, and the flow of cerebrospinal fluid or changes in patient position made the pad shift. However, we doubted that the thickening arachnoid bound the trigeminal nerve.

The primary complication of MVD plus LNS or LNS only treatment was facial numbness in this study. The patients had previously received MVD treatment, and after the recurrence of post-operative pain they were also treated with MVD, BoNT, SRS, PBC or PGR. However, pain continued to recur, and they sought pain relief at our institution. With the addition of longitudinal nerve sectioning, we could accurately observe the position of the corresponding nerve bundle during the surgery and then comb the trigeminal nerve. This technique can effectively relieve pain, but it is also one of the causes of post-operative facial numbness. Other operational techniques can also result in pain relief, but these surgical procedures can also cause facial numbness, to some extent. Ko et al. reported that patients treated with internal neurolysis experienced numbness, but the numbness did not obviously affect their quality of life (20). Gao et al. also reported that MVD and LNS resulted in almost complete pain relief and 
with few complications (13). In our study, although 6 patients experienced facial numbness prior to the procedure, new facial numbness existed in all patients immediately after the operation and 18 patients (85.7\%) still suffered from facial numbness at the end of the follow-up period. This result is believed to be associated with the removal of the Teflon or the combing of the nerve fibers (Table IV).

This study has several limitations. First, all patients were studied retrospectively. This study did not compare the effectiveness, the recurrence rate or the complication rate of different surgical methods, all of which require further study. Second, the sample size was small, and was not enough to conduct a precise analysis. Third, the follow-up period was relatively short. Therefore, larger studies are needed to be conducted over longer periods than 10 years to find a more effective treatment for recurrent $\mathrm{TN}$ after multiple procedures.

\section{CONCLUSION}

The study certifies that vascular compression, arachnoid adhesion and Teflon granulomas were the causes of recurrent trigeminal neuralgia. MVD plus LNS and LNS only are both feasible therapeutic options with good probabilities of success, especially after multiple neurodestructive procedures.

\section{REFERENCES}

1. Amador N, Pollock BE: Repeat posterior fossa exploration for patients with persistent or recurrent idiopathic trigeminal neuralgia. Journal of Neurosurgery 108(5):916-920, 2008

2. Bakker NA, Van Dijk JM, Immenga $S$, Wagemakers $M$, Metzemaekers JD: Repeat microvascular decompression for recurrent idiopathic trigeminal neuralgia. J Neurosurg 121:936-939, 2014

3. Barker FG 2nd, Jannetta PJ, Bissonette DJ, Larkins MV, Jho HD: The long-term outcome of microvascular decompression for trigeminal neuralgia. N Engl J Med 334:1077-1083, 1996

4. Bederson JB, Wilson CB: Evaluation of microvascular decompression and partial sensory rhizotomy in 252 cases of trigeminal neuralgia. J Neurosurg 71:359-367, 1989

5. Broggi G, Ferroli P, Franzini A, Servello D, Dones I: Microvascular decompression for trigeminal neuralgia: Comments on a series of 250 cases, including 10 patients with multiple sclerosis. J Neurol Neurosurg Psychiatry 68(1):59-64, 2000

6. Burchiel KJ, Clarke H, Haglund M, Loeser JD: Long-term efficacy of microvascular decompression in trigeminal neuralgia. J Neurosur 69:35-38, 1988

7. Capelle HH, Brandis A, Tschan CA, Krauss JK: Treatment of recurrent trigeminal neuralgia. J Headache Pain 11(4):339344, 2010

8. Chen J, Lee S, Lui T, Yeh Y, Chen T, Tzaan W: Teflon granuloma after microvascular decompression for trigeminal neuralgia. Surg Neurol 53(3):281-287, 2000

9. Cho DY, Chang CG, Wang YC, Wang FH, Shen CC, Yang DY: Repeat operations in failed microvascular decompression for trigeminal neuralgia. Neurosurgery 35(4):665-669, 1994
10. Cruccu G, Gronseth G, Alksne J, Argoff C, Brainin M, Burchiel $\mathrm{K}$, Nurmikko T, Zakrzewska JM; American Academy of Neurology Society; European Federation of Neurological Society: AAN-EFNS guidelines on trigeminal neuralgia management. Eur J Neurol 15:1013-1028, 2008

11. Du Y, Yang D, Dong X, Du Q, Wang H, Yu W: Percutaneous balloon compression (PBC) of trigeminal ganglion for recurrent trigeminal neuralgia after microvascular decompression (MVD). Ir J Med Sci 184:745-751, 2015

12. Dubey A, Sung WS, Shaya M, Patwardhan R, Willi B, Smith D, Nanda A: Complications of posterior cranial fossa surgery: An institutional experience of 500 patients. Surg Neurol 72(4):369-375, 2009

13. Gao X, Qi W, Li M, Zhang J, Cao Y, Ma Z: To study the clinical valuation of different operation methods in treatment primary trigeminal neuralgia by retrosigmoidal approach. Lin Chung Er Bi Yan Hou Tou Jing Wai Ke Za Zhi 21(14):643-645, 2007

14. Gu W, Zhao W: Microvascular decompression for recurrent trigeminal neuralgia. J Clin Neurosci 21(9):1549-1553, 2014

15. Harrigal C, Branstetter BF, Snyderman $\mathrm{CH}$, Maroon J: Teflon granuloma in the nasopharynx: A potentially false-positive PET/CT finding. AJNR Am J Neuroradiol 26(2):417-420, 2005

16. Huang CF, Chiou SY, Wu MF, Tu HT, Liu WS: Gamma Knife surgery for recurrent or residual trigeminal neuralgia after a failed initial procedure. J Neurosurg 113:172-177, 2010

17. Jannetta PJ: Arterial compression of the trigeminal nerve at the pons in patients with trigeminal neuralgia. J Neurosurg 26:159-162, 1967

18. Jie H, Xuanchen Z, Deheng L, Kun G, Fengyang X, Xiang C, Xiaoting W, Guangxin Z, Yiqing L: The long-term outcome of nerve combing for trigeminal neuralgia. Acta Neurochir 155:1703-1708, 2013

19. Kline DG, Hudson AR: Acute injuries of peripheral nerve. In: JR Y (ed), Neurological Surgery, 1996

20. Ko AL, Ozpinar A, Lee A, Raslan AM, McCartney S, Burchiel $\mathrm{KJ}$ : Long-term efficacy and safety of LNS for trigeminal neuralgia without neurovascular compression. J Neurosurg 122:1048-1057, 2015

21. Manzoni GC, Torelli P: Epidemiology of typical and atypical craniofacial neuralgias. Neurol Sci 26 Suppl 2:s65-s67, 2005

22. McLaughlin MR, Jannetta PJ, Clyde BL, Subach BR, Comey $\mathrm{CH}$, Resnick DK: Microvascular decompression of cranial nerves: Lessons learned after 4400 operations. J Neurosurg 90:1-8, 1999

23. Nurmikko TJ, Eldridge PR: Trigeminal neuralgia-pathophysiology, diagnosis and current treatment. Br J Anaesth 87:117132, 2001

24. Oesman C, Mooij JJ: Long-term follow-up of microvascular decompression for trigeminal neuralgia. Skull Base 21:313322,2011

25. Olesen J: Headache Classification Committee of the International Headache Society. The International Classification of Headache Disorders, 3rd edition (beta version). Cephalalgia 33(9):629-808,2013

26. Premsagar IC, Moss T, Coakham HB: Teflon-induced granuloma follow treatment of trigeminal neuralgia by microvascular decompression. Report of two cases. J Neurosurg 87(3):454-457, 1997 
27. Rogers CL, Shetter AG, Fiedler JA, Smith KA, Han PP, Speiser BL: Gamma knife radiosurgery for trigeminal neuralgia: The initial experience of The Barrow Neurological Institute. Int J Radiat Oncol Biol Phys 47:1013-1019, 2000

28. Sabalys G, Juodzbalys G, Wang HL: Aetiology and pathogenesis of trigeminal neuralgia: A comprehensive review. J Oral Maxillofac Res 3(4):e2, 2013

29. Sandell T, Eide PK: Effect of microvascular decompression in trigeminal neuralgia patients with or without constant pain. Neurosurgery 63:93-99, 2008

30. Sarsam Z, Garcia-Fiñana M, Nurmikko TJ, Varma TR, Eldridge $P$ : The long-term outcome of microvascular decompression for trigeminal neuralgia. Br J Neurosurg 24:18-25, 2010

31. Ugwuanyi UC, Kitchen ND: The operative findings in redo microvascular decompression for recurrent trigeminal neuralgia. British Journal of Neurosurgery 24(1):26-30, 2010

32. Walchenbach R, Voormolen JH, Hermans J: Microvascular decompression for trigeminal neuralgia: A critical reappraisal. Clin Neurol Neurosurg 96:290-295, 1994
33. Yeretsian RA, Blodgett TM, Branstetter BF, Robertsc MM, Meltzer CC: Teflon-induced granuloma: A false-positive finding with PET resolved with combined PET and CT. AJNR Am J Neuroradiol 24(6):1164-1166, 2003

34. Zhang H, Lei D, You C, Mao BY, Wu B, Fang Y: The long-term outcome predictors of pure microvascular decompression for primary trigeminal neuralgia. World Neurosurg 79:756-762, 2013

35. Zhong J, Li ST, Zhu J, Guan HX, Zhou QM, Jiao W, Ying TT, Yang XS, Zhan WC, Hua XM: A clinical analysis on microvascular decompression surgery in a series of 3000 cases. J Clin Neurosci 114:846-851, 2012

36. Zhou X, Liu Y, Yue Z, Luan D, Zhang H, Han J: Comparison of nerve combing and percutaneous radiofrequency thermocoagulation in the treatment for idiopathic trigeminal neuralgia. Braz J Otorhinolaryngol 82:574-579, 2016 